\section{Transradial anterograde recanalization of a totally occluded right coronary artery using a Guideliner catheter}

\section{Revascularización anterógrada mediante acceso arterial radial de una oclusión total crónica de la arteria coronaria derecha usando un catéter Guideliner}

Chronic total occlusions (CTOs) are present in 15-30\% of patients who undergo coronary angiography. ${ }^{1}$ The successful revascularization of a CTO is associated with a reduction in angina symptoms and better long-term survival. Percutaneous coronary interventions (PCIs) for CTO are currently performed with improving success rates and low complication rates. ${ }^{2}$ The use of the transfemoral arterial approach (TFA) is the commonly accepted method for CTO interventions because this approach provides better support. The transradial approach (TRA) for PCl has been shown to have benefits that include shorter hospital stays and a reduction in vascular complications ${ }^{3}$; however, coronary anatomic variations and the lack of guide catheter support increase the technical complexity. ${ }^{4}$ Different strategies have been emerging to resolve the problem of inadequate guide catheter support: the use of high-support guidewires, techniques involving buddy wires and "mother-and-child" guide catheter extension systems among others. In this case report, we applied the Guideliner mother-and-child catheter (Vascular Solutions, Minneapolis, Minnesota, USA) to successfully treat a case of CTO performed through the TRA.

A 69-year-old female with a past medical history of hypertension, dyslipidemia, coronary artery disease and a coronary angioplasty with two drug-eluting stents in the proximal first obtuse marginal artery and the mid-right coronary artery (RCA) 8 years previously presented to our hospital with recurrent angina and was referred for cardiac catheterization. After obtaining informed consent, coronary angiography performed through the TRA revealed an occlusion of the mid-RCA just distal to the previous stent. The distal RCA was observed to backfill following a contralateral injection of the left coronary artery. Therefore, anterograde angioplasty of the RCA CTO was performed from the radial artery using a $6 \mathrm{Fr}$ JR guiding catheter that provided poor support, and the occlusion was not successfully crossed (Fig. 1a). Therefore, a 5-in-6 Fr Guideliner catheter was passed into the mid-RCA and a Pilot 150 (Abbott Vascular, Santa Clara, California, USA) wire crossed the CTO with a $1.0 \mathrm{~mm} \times 10 \mathrm{~mm}$ Falcon CTO (Invatec, Roncadelle, Italy) balloon support (Fig. 1b). Serial predilatations with $1.5 \mathrm{~mm} \times 15 \mathrm{~mm}$ and $2.0 \mathrm{~mm} \times 15 \mathrm{~mm}$ semi-compliant balloons were performed (Fig. 2a), and a $2.5 \mathrm{~mm} \times 38 \mathrm{~mm}$ Xience Xpedition (Abbott Vascular, Santa Clara, California, USA) stent was deployed (Fig. 2b) with a good final angiographic result (Fig. 2c).

The treatment of CTOs remains one of the major challenges of PCls. The most common cause of failure is the inability of the wire to cross the CTO. ${ }^{5}$ The majority of CTO $\mathrm{PCl}$ s are performed through the TFA with larger-sized guiding catheters due to the perceptions of an inability to use such catheters and a lack of support during TRA cardiac catheterization $^{6}$; these perceived factors would typically decrease the rate of procedural success and the need for a crossover to a TFA. The anatomical curve of the RCA is particularly unfavorable compared to the left coronary vessels from the mechanical perspective of device delivery, and the introduction of a guide catheter extension system might increase guide catheter support and facilitate the successful completion of a complex $\mathrm{PCl}$ via the TRA rather than being required to change to the TFA.

Here, we report a simple technique that can be easily used in any catheterization laboratory to increase the procedural success of CTO procedures. In our case, the CTO was performed through the TRA, but good back up of the guide catheter was lacking, so the guidewire was unable to cross the mid-RCA CTO. At this time, rather than changing the vascular access, a 5-in-6 Fr Guideliner catheter was used to complete the procedure. The Guideliner is a coaxial "mother-and-child" catheter mounted on a monorail system that extends the angioplasty-guiding catheter and enables deep intubation of the coronary artery to achieve extra support without displacement of the guiding catheter/wire. The flexible design of this catheter minimizes the risk of catheter-induced vessel dissection, although this complication is not common. ${ }^{7}$ The Twente Guideliner registry describes the feasibility and safety of this catheter based on its use in 65 patients, $97 \%$ of whom had complex coronary lesions (17\% CTO). The TRA was employed in $34 \%$ of
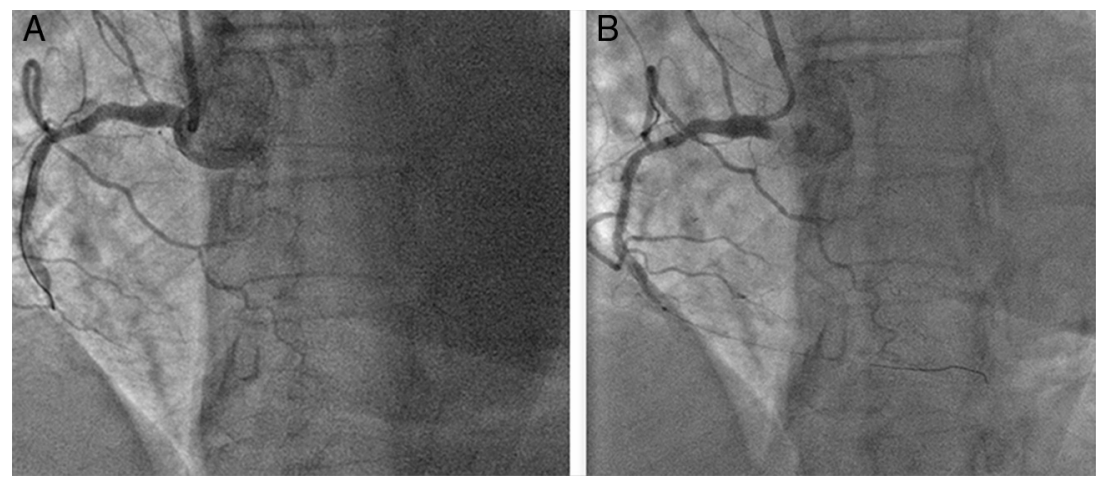

Figure 1 (A) The lack of guide catheter support was the cause of the failure to advance the guidewire and cross the chronic total occlusion (CTO). (B) A Guideliner catheter was advanced and a Pilot 150 wire crossed the CTO. 

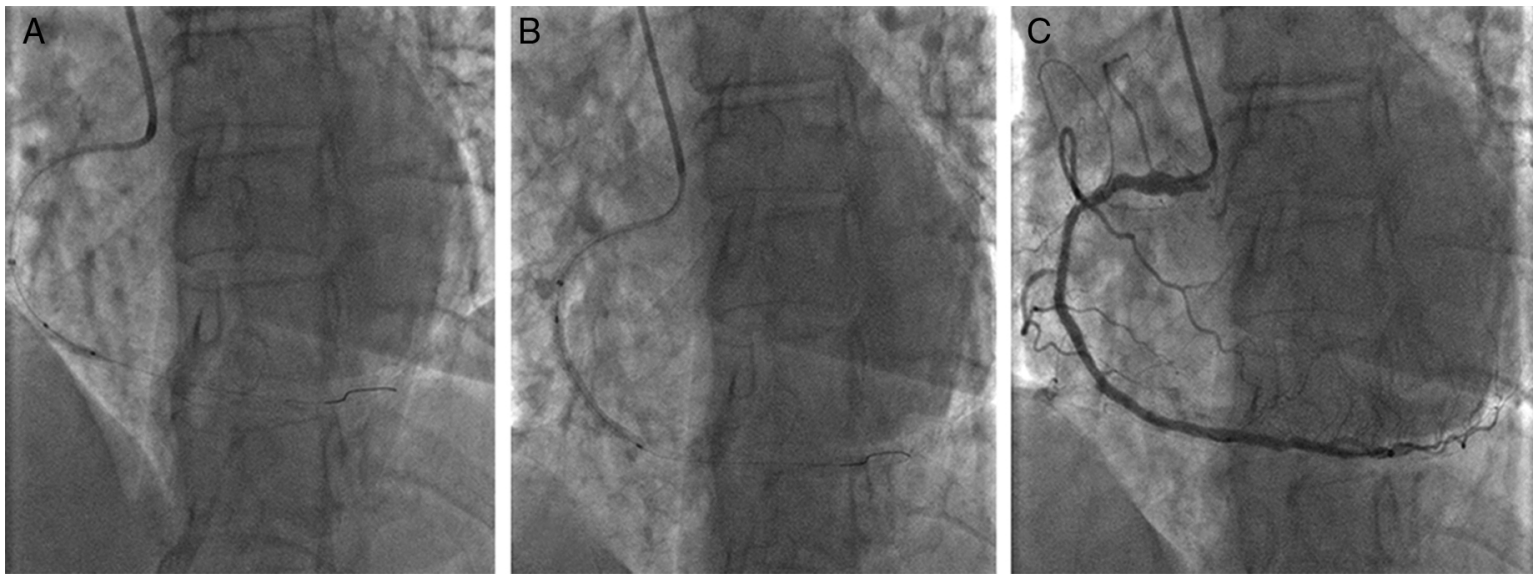

Figure 2 (A) Predilatation with a semi-compliant balloon. (B) Stent implantation was enabled by the deep seating of the Guideliner. (C) The final angiographic result.

these cases, the device success rate was 93\%, and there were no major complications and two minor complications (one air embolism and one stent dislodgement) without clinical implications. ${ }^{8}$ Kovacic et al. ${ }^{9}$ reported a series of 28 patients who underwent $\mathrm{PCI}$ for CTO with the Guideliner catheter. All but one of the CTOs were performed using an anterograde approach, and TRA was used in two cases. The overall procedure success was $89.3 \%$; there was one distal guidewire perforation without hemodynamic compromise or pericardial effusion, and the patient was discharged to home on the following day. Eddin et al. ${ }^{10}$ described 146 TRA cases in which 22 cases (15\%) required use of the Guideliner. The proximal vessel angulation was significantly associated with the need for Guideliner use during the TRA.

The TFA is the method for CTO interventions that is accepted across the world. However, CTO PCls can be performed safely through the TRA in some selected cases and the Guideliner can be successfully used as an adjunctive tool as illustrated by the present case.

\section{Privacy policy}

The authors declare that this article does not appear patient data.

\section{Bibliografía}

1. Fefer P, Knudtson ML, Cheema AN, et al. Current perspectives on coronary chronic total occlusions: the Canadian Multicenter Chronic Total Occlusions Registry. J Am Coll Cardiol. 2012;59:991-7.

2. Patel VG, Brayton KM, Tamayo A, et al. Angiographic success and procedural complications in patients undergoing percutaneous coronary chronic total occlusion interventions: a weighted meta-analysis of 18,061 patients from 65 studies. JACC Cardiovasc Interv. 2013;6:128-36.

3. Jolly SS, Yusuf S, Cairns J, et al. Radial versus femoral access for coronary angiography and intervention in patients with acute coronary syndromes (RIVAL): a randomised, parallel group, multicentre trial. Lancet. 2011;377: 1409-20.

4. Dehghani P, Mohammad A, Bajaj R, et al. Mechanism and predictors of failed transradial approach for percutaneous coronary interventions. JACC Cardiovasc Interv. 2009;2: 1057-64.

5. Noguchi T, Miyazaki S, Morii I, et al. Percutaneous transluminal coronary angioplasty of chronic total occlusions; determinants of primary success and long term clinical outcome. Catheter Cardiovasc Interv. 2000;49:258-64.

6. Egred M. Feasibility and safety of 7-Fr radial approach for complex PCl. J Interv Cardiol. 2011;24:383-8.

7. Cola C, Miranda F, Vaquerizo B, Fantuzzi A, et al. The Guideliner catheter for stent delivery in difficult cases: tips and tricks. J Interv Cardiol. 2011;24:450-61.

8. Mamas MA, Fath-Ordoubadi F, Fraser DG. Distal stent delivery with Guideliner catheter: first in man experience. Catheter Cardiovasc Interv. 2010;76:102-11.

9. Kovacic JC, Sharma AB, Roy S, et al. GuideLiner mother-andchild guide catheter extension: a simple adjunctive tool in $\mathrm{PCl}$ for balloon uncrossable chronic total occlusions. J Interv Cardiol. 2013;26:343-50.

10. Eddin MJ, Armstrong EJ, Javed U, et al. Transradial interventions with the guideliner catheter: role of proximal vessel angulation. Cardiovasc Revasc Med. 2013;14:275-9.

Javier Benezet*, Alejandro Gutiérrez-Barrios, Antonio Agarrado, Jesús Oneto

Department of Cardiology, Hospital de Jerez de la Frontera, Jerez de la Frontera, Cádiz, Spain

* Corresponding author at: Servicio de Cardiología, Hospital de Jerez de la Frontera, Circunvalación s/n, 11407 Jerez de la Frontera, Cádiz, Spain.

E-mail address: javbenezet@hotmail.com

(J. Benezet).

http://dx.doi.org/10.1016/j.acmx.2014.12.004 